Universities Council on Water Resources

Journal of Contemporary Water RESEARCH \& EducAtion

ISSUE 131, PAgES 55-59, JUNE 2005

\title{
The Role of Science in Balancing the Needs of Protected Species: An Historical Perspective
}

\author{
Michael G. Thabault \\ U.S. Fish and Wildife Service
}

$\mathrm{S}$ ince the Endangered Species Act was passed in 1973, there have been approximately 514 animal species listed. Of those, at least 258 are aquatic species or aquatic dependant species. As one would expect, the ranges, distributions, and ecological needs of many of these species overlap. Also, due to changes in the physical environment, species have been significantly restricted to a fraction of their former range; some even may now reside where they historically had not. As a result, there may be significant conflict between the varying needs of different listed species now restricted to the same limited areas, often outside the preferred range of at least one of the species; these conflicts are further complicated when the areas involved are critically important for societal needs. However, science provides us with valuable tools to help manage these conflicts. This paper will hopefully illustrate the application (or lack of application) of these tools in the management of several such conflicts.

\section{Chinook Salmon}

The National Marine Fisheries Service (NOAA Fisheries) listed winter-run chinook salmon in the Sacramento River in the Central Valley of California as a threatened species in 1990 (subsequently reclassified as endangered in 1995). Winter-run chinook historically began their spawning run up the Sacramento River in December and continued through June. Spawning would occur typically in April through July. Rearing and out-migration would continue throughout the spawning period on spring flows. Prior to the construction of Shasta Dam on the upper Sacramento River, winter-run chinook would go past the present dam site into the upper Sacramento, Pit, and McCloud Rivers. The glacial melt that stimulated spawning would also keep the temperature of the water in the rivers very cool, providing optimal rearing conditions. This race of chinook salmon became adapted to this ecological niche.

When Shasta Dam, and its reregulating reservoir downstream (controlled by Keswick dam), were built no provision for upstream passage by salmon was provided. Winter-run chinook salmon were effectively precluded from virtually all the historical spawning habitat that had been upstream of Keswick. The construction of Red Bluff Diversion Dam, approximately 30 miles downstream of Keswick, which provides irrigation supply to the Tehama Colusa Canal, further precluded upstream passage by salmon. Faced with these extreme changes to the river system in which they evolved, it is perhaps suprising that winter-run chinook salmon were not extirpated soon after construction of Shasta, Keswick, and Red Bluff dams. However, Shasta Dam was regularly operated for hydropower production which meant that water was released at an elevation on the dam to accommodate the turbines. When the reservoir was full these releases were cold and created suitable downstream environmental conditions for winter-run chinook salmon spawning and rearing; winter-run chinook salmon were soon observed using new spawning habitat below Keswick Dam. Unfortunately the dam was not always full. When the reservoir was low the releases were warm, creating adverse conditions for winter-run chinook salmon. This series of 
physical changes to the environment "forced" the winter-run chinook salmonout of its historical range and straight into the path of water development in the Central Valley of California.

The listing of winter-run chinook salmon was determined appropriate because the population of spawning adults returning to the river had declined from over 100,000 individuals in the late 1960 s to less than 200 at the time of listing. Additionally, NOAA Fisheries concluded that the continued operation of the Central Valley Project, specifically Shasta Dam and Red Bluff Diversion Dam were significant threats to the species.

\section{Delta Smelt}

At the lower end of the Sacramento Valley, in the Sacramento-San Joaquin Delta (hereafter Delta), the U.S. Fish and Wildlife Service listed the delta smelt as a threatened species in 1993. The delta smelt is a small, mostly annual fish that resides in the Delta, Suisun Bay, and Suisun Marsh. Historically, this species began its spawning migration from Suisun Bay as early as February and continued through April and early May. Spawning occurred from March through May but could have been as late as mid-June in drier years. The species has a very narrow salinity tolerance. Historically, the appropriate salinity range moved over a relatively broad geographic extent and was controlled by the amount of spring outflow.

The Delta is the location where state and federal water projects divert water to agricultural and municipal purposes in the San Joaquin Valley and Southern California. The Federal Central Valley Project (CVP) began diverting from the Delta in 1939. The State Water Project (SWP) began diverting from the Delta in 1968. Combined they diverted as much as $70 \%$ of the inflow into the Delta, up to 6.1 million acre feet annually. These two water projects modified the physical environment in two principle ways related to the delta smelt. First was the construction of the dams themselves. The Central Valley is a spring snowmelt system. Historically the rivers peaked in flow in April and May as the Sierra snowmelt occurred; the dams were developed to capture the snowmelt for water supply and thereby prevent it from arriving in the Delta. In addition, the export pumps significantly affected habitat conditions in the Delta itself. The diverted fresh water was replaced in the Delta by higher salinity water from the Bay. This resulted in a constriction of suitable habitat based on salinity.

These examples highlight how the physical changes to this system have affected these two species, and increased the potential for conflict both between the two species and between the species and California's water supply needs. Prior to water development there would have been no potential conflict between these species' life histories. Now, however, both species depend on timely releases from Shasta Dam-at times which don't always match up, and may not be consistent with the seasonal needs of California's agricultural and urban water users. The essence of the potential conflict was the tension between releasing water for Delta water quality and retaining water for temperature management. This is a situation that is not just confined to the upper Sacramento River but exists for all major tributaries to the Sacramento and San Joaquin rivers and for many other runs of salmon in the Central Valley.

There was a substantial amount known about these species at the time of their listing, including some knowledge of the ecological functions and physical habitat characteristics necessary for their survival. However, for the many years during their decline, prior to protection under the ESA, there was very little targeted monitoring and evaluation of them. Additionally, there was very little done in a proactive manner prior to listing to modify the physical threats to the species in order to preclude listing, even though all of the signs were present. Even following their listing, true adaptive management and monitoring programs were not established for winter-run smelt for about a decade and about 4 to 5 years for delta smelt. Only now are we truly reaping the benefits of additional knowledge on how to manage this system for the species while providing for the purposes of the water project with a higher degree of certainty.

Some very significant interruptions in project operations due to listed species issues forced people to the table to evaluate the scientific capabilities in order to refine management around real time data. Significant reductions in pumping and water supply deliveries coupled with critical habitat designations, additional species listings, and new water quality standards for the Delta, largely developed around the needs of the fish, galvanized the Valley's 
motivation to come to the table. It was the BayDelta Accord (signed in 1994), which launched the CalFED Bay-Delta Program in 1995. CalFED has not attained true adaptive management yet because the essence of adaptive management is determining the uncertainties and then designing focused experiments to resolve the uncertainties. CalFED has implemented only a few experiments. Part of the uncertainty that agencies and stakeholders had to wrestle with was: If you managed temperature for winter-run through the summer would you sufficiently deplete available storage thereby risking spring salinity management in the Delta? The flip side of this is that water would be released from storage to meet water quality standards, depleting the cold water pool in the reservoir. CalFED is very early in implementing its "experiment" and only time will tell whether sufficient momentum has been gained to reverse the trends for these species. Early results appear very promising.

So where does this very brief case study lead and what kind of implications does it have for other similar, controversial programs such as the Platte River Recovery Program, the Missouri River, the Rio Grande, the Pecos? My qualitative assessment and unscientific view of the world leads me to conclude that despite obvious signals of ecological and species decline, there is generally an unwillingness to invest in structured science before a crisis (e.g., listing a species under the ESA or some operational constraint). This lack of advance scientific endeavor leads to a lack of targeted longterm data sets that in-turn creates a void of new science and delayed knowledge once a species has been listed. Additionally, our traditional emphasis on species specific information and focus on minimum requirements undermines multi-species, landscape scale management.

In the CalFED process, as is the case in many of these highly complex and controversial programs, it took strong leadership from the stakeholder community to not just talk about the lack of science but bring resources to the table to help it along. This does not include just funding and other resources. Stakeholders and non-agency staff have brought challenges to the existing paradigms and old ways of doing business - and importantly, an interest in jointly finding a way to operate the system better for all its needs. This is not to say what the agencies had been doing was wrong, but that a willingness to collaborate for change establishes an environment where agencies are willing to take risks in the interest of obtaining results. As noted by David Hayes (2002), other elements need to be present, perhaps especially a forcing event which creates a tipping point for people to move off of positions and political leadership to bring parties to the table and get results.

Another issue I have observed is that often the evaluation that results from regulatory action confirms the false belief that there is only one answer. Again, through the lack of upfront information on uncertainties, agency personnel must act on the information they have. This often leads to a prescriptive solution because of the lack of information to assess alternative courses of action. The structure of the statutes and regulations are interpreted often as giving little flexibility to manage in the interest of protecting the resource while minimizing impacts. The prescriptive solution becomes the only scientifically supportable solution, in part because a lack of information or the presence of conflicting information makes agency personnel risk-averse. In some respects this was the real time ramification of the Klamath situation.

The Klamath is a situation again where multiple species are involved (suckers in the upper basin and salmon in the lower basin) and where science is less than complete despite the fact the suckers in the upper basin have been listed under the ESA since 1988 and coho salmon since 1997. The endangered Lost River sucker and the short-nosed sucker reside in Upper Klamath Lake and upstream portions of the watershed. Downstream of Upper Klamath Lake reside the threatened coho salmon. The suckers of Upper Klamath Lake have suffered significant mortality events for which the specific causes are unclear. There is a certain body of data that indicates poor water quality has occurred in Upper Klamath Lake, but not necessarily at the same time as the mortality events. Coho salmon utilize both the mainstem and the tributaries of the Klamath River but at different times of the year. The Service and NOAA Fisheries came to the independent conclusions that sucker survival depends on nondramatic changes in the lake level and that there should be minimum instream flows for coho salmon to ensure their survival. These decisions, coupled with the natural event of drought set a recipe for disaster in the summer of 2001. 
The ESA does not provide for the Service or NOAA Fisheries to not act pending additional information. They are charged with making decisions based on the information at hand. The lack of precision in the science often leads the agencies to choose conservative alternatives with relatively little flexibility. A result is that there is little room to maneuver or find creative solutions when a crisis hits. The results of the agencies' evaluation becomes "the" answer. Advanced scientific knowledge would have provided the agencies more guidance on where flexibility lies and how to formulate an adaptive management program that would resolve some of the remaining uncertainties in the Klamath Basin.

The National Research Council (National Research Council 2004) evaluated the science behind the decisions of the agencies in the Klamath basin and concluded that the vast majority of those decisions were appropriate and that exercise of judgment was not outside the bounds of scientific knowledge. However, they did conclude that in certain instances that there was a lack of clear science to justify the decision. In fact, they concluded that there may actually be data that would be counter to the conclusions reached by the agency. The NRC concluded that a basin wide effort of recovery implementation and participation by others in the basin was essential for success. Implicit in these conclusions, and discussions early in the report about the lack of data, leads me to think that a more collaborative process initiated earlier may have avoided this crisis.

The current Missouri River situation illustrates a similar path. The Missouri River is currently home to three listed species: Interior least terns, Great Plains piping plovers, and pallid sturgeon. The Missouri River traverses seven states in the central plains of the U.S. There happens to be fairly good information on population status and trends across the range of the piping plover. However, there is no range-wide or basin-wide coordinated scientific effort to evaluate and manage the least tern or the pallid sturgeon. The Missouri River was historically, and to a certain degree currently is, a highly dynamic system. The three species, as well as numerous other native species in the basin, have principally suffered and declined because of the loss of physical form and function of the river. There appears to be little debate on this point. However, because of the lack of a comprehensive scientific study of the basin, there is currently no agreement on precisely how much of that form and function must be returned to the river to stem the decline of these species, especially the pallid sturgeon.

The Service took the position in 2000 that some semblance of form and function needs to be restored to the Missouri River in order to ensure the survival of these species. As a result the Service prescribed an approach. In 2003, the Service was again asked to reconsider its approach. The Service continued to conclude in 2003 that some semblance of form and function needed to be restored to the Missouri River to ensure the survival of the pallid sturgeon. The Service did, however, modify the specific measures required. There was substantial litigation associated with this issue. The essential arguments were: 1) there is insufficient science to do anything, 2) the science is so clear that the Service should have never deviated from their original conclusion. The court ultimately decided that the basic course laid out at the end of 2003 was defensible. Despite years of conflict in the basin and in the courts I offer that we are not much better off in our understanding of what works and what does not work ecologically in the Missouri River. Although the courts have ruled on the basic framework, to ensure success for all interests it takes leadership and people collaborating on the science; both appear to be lacking in the basin.

Despite a long history of conflict there has, as yet, not been sufficient coalescence around dedicating the resources to implement a comprehensive monitoring and adaptive management program. Even after 2000, when there could have been a tipping point, there was only further polarization that yielded very little new information that the Service could evaluate in 2003. Even with judicial resolution of the legal questions there will have to be leadership at the affected parties' table to work out a practical and (biologically and socially) supportable solution. Recently, in trying to comply with one component of the biological opinion, the Army Corps of Engineers proposed to construct an unprecedented amount of shallow water habitat in the Missouri River. Their basic premise was to springboard off work that had been done since the mid-1970s. Remarkably, after 35 years of implementation, there was very little empirical data that indicated the reliability or efficacy of the course chosen by the Corps. Therefore, there remains great uncertainty as to the degree of impact that the Corps' recent actions will have on the 
biological environment. Only with dedicated adaptive management and monitoring will we be able to remove some of the uncertainties and maximize biological benefits.

In conclusion, I glean the following lessons from the past to help guide the future. First, there are numerous species that are in decline and are considered to be candidates for protection under the ESA. Many of these are already in areas where other species are currently afforded protection and for which management is currently being applied. There may well be very little structured science being conducted to evaluate what may be the conservation needs of these candidate species and the possibility of incorporating those needs into the management for species that are already protected. The more upfront work, at the system-wide level, that is done now the more flexibility will be available later because of the knowledge developed. However, there may be sufficient information now to develop starting points for actions, within an adaptive management framework, to avoid crisis. An advance on investment, in terms of money, human resources, and collaborative processes may likely save money and resources in the long-term.

Secondly, those agencies and stakeholders that are involved in these highly complex issues must choose to deviate from positional and advocacy science into a collaborative process to develop viable adaptive management programs. Only through collaboration will there be certainty for all sides. This will require that agencies assume some short-term risk for long-term gains in knowledge and management flexibility. For stakeholder communities, it requires that they assume some risk of short-term impacts in order to establish longer-term management flexibility and stability.

Third, in order to have a sustainable and defensible process and outcome, the development of adaptive management programs must be transparent and subject to outside review. Only through ownership and understanding will all the parties accept and support the results. Progress can be made as long as people are focused on interpreting results that flow from an agreed upon program. If there is suspicion because the program was developed with a smaller subset of the community, certain interests will want to focus on why or how results were obtained, rather than focusing on the results themselves. If done properly, outside independent review will validate the program and insulate and defend against the extremes. Independent outside review gives any interest in the process the legitimacy to force change if the science is supported.

Lastly, science should focus on mechanisms and ecological processes leading to desired outcomes, rather than setting precise criteria. Knowing what you want to achieve and the mechanisms (physical or chemical processes, etc.) that are relevant to the objectives allows for a reasonable starting point from which to assess and manage change. By establishing this type of approach, agencies and stakeholders can react to unusual circumstances without violating the boundaries of the regulatory construct. It is also an admission that we probably don't know enough about these large systems to give the definitive answer today or even tomorrow. The bottom line, from the agency perspective, is that decisions must be made and starting points must be established. Other interested parties must be assured that the starting points are reasonable and that agencies will respond to information, even if it means moving away from prior established positions.

\section{Author Bio and Contact Information}

Michael Thabault is currently Assitant Regional Director in the U.S. Fish and Wildlife Service's Northeast Regional Office. Prior to that he was a Water Consultation Biologist with the Headquarters office of the U.S. Fish and Wildlife Service (Service) with 17 years of Federal service. He has worked on Western water issues since 1990. First, while with NOAA Fisheries and subsequently with the Service. He has been actively involved with the CalFED Bay-Delta Program since its inception. Most recently he has been working with issues involving the operation and management of the Missouri River. He has a bachelor of science in biology from the University of Oregon. He can be reached at: U.S. Fish and Wildlife Service, 300 Wesgate Center Drive, Hadley, Massachusetts 01035. Telephone,(413)253-8304.michael_thabault@fws.gov.

\section{Acknowledgement}

I would like to thank Patrick Leonard for his review and editorial advice on this paper.

\section{References}

Hayes, D. J. 2002. Federal and state decisionmaking on water: Applying lessons learned. Environmental Law Reporter 32: 11253-11262.

National Research Council (NRC). 2004. Endangered and threatened fishes in the Klamath River Basin: Causes of decline and strategies for recovery. Washington, DC: National Academy Press. 